\title{
Parental Practices of High School Students with ADHD Behaviours: A Study
}

\author{
Dr. G. Venugopal ${ }^{1 *}$, Karanam Mahaboobvali ${ }^{2}$
}

\section{ABSTRACT}

Attention deficit hyperactivity disorder (ADHD) is a disorder that appears in early childhood. ADHD makes it difficult for people to inhibit their spontaneous responses that can involve the lot from movement to speech to attentiveness. The present study focus on the parental practices of high school students with ADHD behaviours- A study. Objectives of the study are To develop a tool to study the parental practices of high school students with ADHD behaviours. To find out the background factors of parents of students with ADHD behaviours. To find out the significant differences, if any, in the parents parental practices of students with ADHD behaviours due to variation in their child's (i) Gender (.ii) Age group (iii) Community (iv) Location of Residence.

Keywords: Disorder, Spontaneous, Parents, Parental And Practices.

Attention deficit hyper activity disorder (ADHD) is a common neurobiological condition affecting 5-8\% of school age children although most cases of ADHD are diagnosed in children when they enter school for the first time, a growing number of children younger than 6 years old are being diagnosed. Children with ADHD are at risk for potentially serious problems in social relations, risk for antisocial behaviour patterns, teen pregnancy, and adverse driving consequences. Symptoms often attenuate during late adolescence although a minority experiences the full complement of symptoms into mid-adulthood.

There is little agreement on the causes of ADHD, because so many different types of characteristics come under this category. There is no single or a primary causes of ADHD: there are many causes for the problems. There are proponents, who view that the problem lies in the child's environment and situations outside the child (e.g. inappropriate behaviour management techniques, lack of appropriate reinforcement etc). There are those, who view that the problem lies within the child. Both view points are true some extent. The definition of ADHD implies that the problem is related to the central nervous system (neurological deficit). The neurological deficit could be the result of genetic, prenatal, peri-natal and postnatal factors. The three primary characteristics of ADHD are i) Inattention, ii) Hyperactivity and iii) Impulsivity. Several factors

\footnotetext{
${ }^{1}$ Academic Consultant, Dept of LTT, Dravidian University, Kuppam, Andhrapradesh, India

${ }^{2}$ Research Scholor, Dept of Education, Dravidian University, Kuppam, Andhrapradesh, India (C) 2016 I G Venugopal, K Mahaboobvali; licensee IJIP. This is an Open Access Research distributed under the terms of the Creative Commons Attribution License (http://creativecommons.org/licenses/by/2.0), which permits unrestricted use, distribution, and reproduction in any Medium, provided the original work is properly cited.
} 
are reported to associate with ADHD. Chief among them are: Bio-physical, Environmental and Psycho-social.

Parenting similarity may also parents own well-being in their parenting role, including parenting stress, satisfaction, and self efficiency? These three interrelated constructs are associated with children's mental health. Mothers of ADHD children report greater parenting stress and lower satisfaction and self-efficacy than mothers of normal children. Among children with ADHD, parenting stress has been associated with disruptive behaviour problems. There are several reasons why parenting similarity might affect parenting well-being first, effects of parenting similarity on marital functioning may spill over to parenting well-being. For example, marital conflict arising from parental dissimilarity might leave parents with fewer emotional resources to cope with stressors presented by their children. In fact, martial quality has been linked to parenting stress. Second, parents with dissimilar parenting approaches may exhibit more unsupportive and less supportive co-parenting behaviour toward one another. Unsupportive and less supportive co-parenting behaviour toward one another. Unsupportive co-parenting behaviour might make parents feel alone and overwhelmed by the challenges presented by their children, resulting in an increase in parenting stress. Unsupportive co-parenting may also lead parents to question their own parenting effectiveness and thereby decrease parenting self esteem.

Understanding the role of parenting similarity in the behaviour of students with ADHD behaviours could have important implications for treatment of these children. Parent training is one of the recommended treatments of these children. If parents practices influences ADHD children's behaviours and family functions.

The above literature clearly indicates that parental practices may have significant bearing on behaviours of children. Poor parental practices lead to development of unhealthy behaviours which in term nurture ADHD behaviours in students. The present study is an attempt to identify parental practices of students with ADHD behaviours.

\section{Objectives of the Study}

1) To develop a tool to study the parental practices of high school students with ADHD behaviours.

2) To find out the background factors of parents of students with ADHD behaviours.

3) To find out the significant differences, if any, in the parents parental practices of students with ADHD behaviours due to variation in their child's (i) Gender (.ii) Age group (iii) Community (iv) Location of Residence

\section{Hypotheses of the Study}

4) There is significant difference in the parents parental practices of students with ADHD behaviours due to variation in their child's (i) Gender (.ii) Age group (iii) Community (iv) Location of Residence 


\section{METHODOLOGY}

The survey method used in this study, the investigator identified 50 high school students of ADHD behaviours through teacher's observation, observation by the researchers and a rating scale developed for the purpose. Identified ADHD students parents were contacted in their residence and explained the purpose of the study. The available parents either father or mother has been asked to respond to the each item of the parent's parental practices two point rating scale. Thus the total sample for the study is 50 parents having the child with ADHD behaviours. As the study having specific purpose, the investigator used only the purposive sampling technique.

Number and percentage of the Parental Practices of Students with Poor, Moderate and Good Level of ADHD Behaviours

One of the major objectives of the study is to assess the level of parental practices of the high school students. To know the number percentage of students under poor, average and good parental practices, the scores has been divided into three groups i.e. low, moderate and high levels by using mean, $\pm 1 \mathrm{SD}$. The number and percentage of parents falling under different levels of parental practices are worked out and are presented in table-1.

Table-1: Number and Percentage of parents with Good, Moderate and Poor

\begin{tabular}{|c|c|c|c|c|c|c|c|}
\hline \multirow{4}{*}{\multicolumn{2}{|c|}{$\begin{array}{lr}\text { Parent } & \text { Parental } \\
\text { Practices of } & \text { Students } \\
\text { with } & \text { ADHD } \\
\text { Behaviours } & \end{array}$}} & \multicolumn{6}{|c|}{ Level of Intensity of Practices } \\
\hline & & \multicolumn{2}{|c|}{ Good } & \multicolumn{2}{|c|}{ Moderate } & \multicolumn{2}{|c|}{ Poor } \\
\hline & & No. & $\%$ & No. & $\%$ & No. & $\%$ \\
\hline & & 6 & $12 \%$ & 36 & $72 \%$ & 8 & $16 \%$ \\
\hline
\end{tabular}

Note: Total number of sample $=\mathbf{5 0}$

In table-1: Indicate that 12 percent of parents are good level of parental practices followed by 72 percent of them with average level of parent parental practices and 16 percent with poor parental practices.

Part-II: Differential analysis - Influence of Independent variables on the parental practices of students with ADHD Behaviours

In order to study the significant difference between two or more groups of a sample, differential studies are useful. For this mean score of the two or more groups of a sample, differential studies are useful. For this mean scores of the two or more number of groups of the sample are compared.

This part is confined to study the parental practices of students with ADHD behaviours due to variation in their personal (independent) variables. Such as gender, age, community, location of residence, birth order of the students, family size, parental occupation, parental income, mode of stay (single/ both parents). The obtained results are presented in the form of tables and discussed. 
Influence of 'Gender' on the Parents Parental Practices of Students with ADHD Behaviours

The mean and standard deviation scores of parental practices of ADHD behaviours of 'Boys and Girls’ and the calculated t-value are presented in the table-2.

Table- 2: Mean and Standard deviations scores of Parents Parental Practices and the calculated t- value based on their children's Gender

\begin{tabular}{|l|l|l|l|}
\hline Gender & Mean & SD & $\begin{array}{l}\text { Calculated } \\
\text { t-value }\end{array}$ \\
\hline Boys (N=30) & 29.60 & 9.45 & $0.69 @$ \\
\cline { 1 - 3 } Girls (N=20) & 30.10 & 4.13 & \\
\hline
\end{tabular}

Note: @ Not significant at 0.05 level

In table-2, the stated hypothesis, 'there exist significant differences in the parent's parental practices of students with ADHD behaviours due to variation in their children gender (boys and girls)', is rejected as the calculated t-value 0.69 is not significant at 0.05 level. It means, the high school student's age has not significantly influenced their parent's parental practices. Other senses, irrespective of 'Gender' of the high school students the parental practices of their parents are same:

From the above, it is concluded that, the variable student 'gender' of high school students has not significantly influenced their parent’s parental practices.

\section{Influence of 'Student Age' on the Parental Practices of High School Students with the ADHD Behaviours}

The mean and standard deviation of the ADHD behaviours scores of below 14 years, 14 years and above age group students and the calculated t-value are presented in the table-3.

Table-3, Mean and Standard Deviation Scores of Parents parental Practices (below 14 years and above 14 years students) and the calculated t-value

\begin{tabular}{|l|l|l|l|}
\hline Student Age & Mean & SD & Calculated t-value \\
\hline Below 14 years $(\mathrm{N}=33)$ & 29.42 & 5.56 & \multirow{2}{*}{$0.02 @$} \\
\cline { 1 - 3 } 14 years above $(\mathrm{N}=17)$ & 29.44 & 8.64 & \\
\hline
\end{tabular}

Note: @ Not Significant at 0.05 level

In table-3, the stated hypothesis, 'there exists significant difference in the parents' parental practices of students with ADHD behaviours due to variation in their children age group (below 14 years and above 14 years)', is rejected as the calculated t-value 0.02 is not significant at 0.05 level. It means, the high school student's age has not significantly influenced their parents' parental practices. Other senses, irrespective of 'Age Group' of the high school students the parental practices of their parents are same. From the above, it is concluded that, the variable 
'student age' of high school students has not significantly influenced their parent's parental practices.

\section{Influence of 'Parents Age' on the Parental Practices of High School Students on the ADHD Behaviours}

The mean and standard deviation scores of the parental practices of 25-45 years and 46 and above age group of parents and the calculated t-value are presented in table- 4 .

Table-4, Mean and Standard Deviation Scores of Parents Parental Practices of High School Students and the calculated t-value based on their Age.

\begin{tabular}{|l|l|l|l|}
\hline Parents Age & Mean & SD & $\begin{array}{l}\text { Calculated } \\
\text { t-value }\end{array}$ \\
\hline Between 25-45 (N=38) & 29.07 & 8.09 & \multirow{2}{*}{$1.66 @$} \\
\cline { 1 - 3 } 46 above $(\mathrm{N}=12)$ & 30.5 & 6.35 & \\
\hline
\end{tabular}

Note: @ Not Significant at 0.05 Level

In table-4, the stated hypotheses, 'there exists significant difference in the parent's parental practices of students with ADHD behaviours due to variation in parental age group (between 2545 years and 46 and above years)', are rejected, as the calculated t-value 1.66 is not significant at 0.05 level. It means, the parent's age has not significantly influenced their parental practices. Other sense, irrespective of 'parent age group' of the high school students, the parental practices of the parents are same.

From the above, it is concluded that, the variable 'parents age' has not significantly influence their parents parental practices.

Influence of 'Nature of Community' on the parental practices of High School Students with ADHD Behaviours

The mean and standard deviation of the parental practices scores of parents from BC and SC \& ST community and the calculated t-value are presented in table-5.

Table:5, Mean and Standard Deviation Scores of Parents Parental Practices of High School Students with ADHD Behaviours and the calculated t-value based on their Community

\begin{tabular}{|l|l|l|l|}
\hline Nature of Community & Mean & SD & Calculated t-value \\
\hline BC (N=37) & 29.74 & 4.87 & \multirow{2}{*}{$0.43 @$} \\
\cline { 1 - 2 } SC \& ST (N=13) & 29.3 & 11.77 & \\
\hline
\end{tabular}

Note: @ Not Significant at 0.05 Level

In table-5, the stated hypothesis, 'there exist significant difference in the parents parental practices of students with ADHD behaviours due to variation in their community (BC, SC\&ST)' is rejected, as the calculated t-value 0.43 is not significant at 0.05 level. It means, the community 
of the parents has not significantly influenced their parental practices. Other senses, irrespective of the 'nature of community', the parental practices of parents with ADHD behaviour children are same. From the above, it is concluded that, the variable 'community' has not significantly influenced the parent's parental practices.

\section{Influence of 'Location of Residence' on the Parental practices of High School Students with ADHD Behaviours}

The mean and standard deviation of the parental practices scores of parents residing in rural and semi urban area and the calculated t-value are presented in table-6.

Table-6, Mean and Standard Deviation Scores of Parents Parental Practices of the calculated t-value based on their Location of Residence (Semi Urban and Rural)

\begin{tabular}{|l|l|l|l|}
\hline Location of Residence & Mean & SD & Calculated t-value \\
\hline Rural (N=40) & 29.88 & 6.38 & \multirow{2}{*}{$1.09 @$} \\
\cline { 1 - 3 } Semi Urban (N=10) & 28.8 & 8.15 & \\
\hline
\end{tabular}

Note: @ Not Significant at 0.05 Level

The stated hypothesis, 'there exist significant difference in the parents parental practices of students with ADHD behaviours due to variation in their location of residence (rural/ semi urban)', is rejected in table-6, as the calculated t-value 1.09 is not significant at 0.05 level. It means, the location of residence has not significantly influenced their parent's parental practices. Other sense, irrespective of the 'location of residence', of the high school students the parental practices of parents with ADHD behaviour students are same.

From the above, it can be concluded that, the variable 'location of residence' of high school students has not significantly influenced the parent’s parental practices.

\section{FINDINGS AND CONCLUSION}

\section{Part-I: Descriptive Analysis:}

1) The mean scores of parental practices of students with ADHD behaviours and the level of intensity of the some in high school students in table-1, it is clear that out of 20 aspects. 3 aspects (serial numbers 1,2 and 12) are having low intensity level of causing poor parental practices of students with ADHD behaviour. In 13 aspects (serial numbers $3,4,5,6,7,8,9,10,11,13,15,17,18$ and 20) the parents parental practices are at moderate levels signifying average levels of practices. In 4 aspects (serial number 6,14,16 and 19) their practices are good enough signifying higher levels of intensity of parental practices

2) The study revealed that $12 \%$ (percent) of parents are good level of parental practices followed by $72 \%$ (percent) of them with average level of parent's parental practices and 16\% (percentage) with poor parental practices. 


\section{Part-II: Differential Analysis:}

3) The variable 'Gender' has not significantly influenced the parent's parental practices of students with ADHD behaviours.

4) The study concluded that the variable 'Students Age' has not significantly influenced the parent's parental practices of students with ADHD behaviours.

5) The variable 'Parents Age' has not significantly influenced the parent's parental practices of students with ADHD behaviours.

6) The variable 'Nature of Community' has not significantly influenced the parent's parental practices of students with ADHD behaviours.

7) The variable 'Location of Residence' has not significantly influenced the parent's parental practices of students with ADHD behaviours.

\section{REFERENCES}

American Psychiatric Association (2000) Diagnostic and Statistical Manual of Mental Disorders: DSM IV (Fourth ed., text and revision), Washington, D.C: American Psychiatric Association.

Eigenmann, P.A. and Haenggeli, C.A. (2007) Food Colourings, Preservative and Hyperactivity. Lancet, 370, 1524-1525.

Faraone, S.V., Biederman, J and Mick, E. (2006) The Age Dependent Decline of Attention Deficit Hyperactivity Disorder: A Meta Analysis of Fellow up Studies. Psychological medicine, 36, 159-65.

Kamlinimayavaramban, T.V., (2011) Effectiveness of Cognitive, Meta cognitive and Behavioural Approaches in overcoming Specific Learning Difficulties in ADHD Children. Dept. of Education, Alagappa University, Karaikudi, 31-39.

Konofal, E. (2004) Archives of Paediatric and Adolescent Medicine, 158,1113-1115.

Reddy, G.L., Shyamala, V., Kusuma, A. and Santhakumari, P. (2004). Antisocial behaviour in students : Detection and management. Discover Publishing House, New Delhi.

How to cite this article: G Venugopal, K Mahaboobvali (2016), Parental Practices of High School Students with ADHD Behaviours: A Study, International Journal of Indian Psychology, Volume 3, Issue 3, No. 9, DIP: 18.01.165/20160303, ISBN: 978-1-365-13820-1 